\title{
Research on the impact of upstream reservoirs regulation on the operation of Xiluodu Reservoir
}

\author{
LIANG Zhiming $^{1, \mathrm{a}}$, Gao Fengxian ${ }^{1}$, Zhang Hairong ${ }^{1}$, REN Yufeng ${ }^{1}$, Xiao Yao $^{2}$ \\ ${ }^{1}$ China Yangtze Power Co., Ltd., Yichang 443133, China \\ ${ }^{2}$ Yichang Shanghai Middle School, Yichang 443100, China
}

\begin{abstract}
In order to explore the influence of reservoirs regulation in the upper basin of Xiluodu Reservoir, 11 key reservoirs in the upper reaches of Xiluodu Reservoir are studied. Based on the analysis of its overall regulation performance, the data of upstream reservoir group from 2006 to 2016 is used to analyze the impact of the upstream reservoir group. By dividing scheduling period of Xiluodu Reservoir into different stages, the impact of each stage and the proportion of impacts of each river basin is analyzed, the degree of impact of each basin is clarified. The results reveals that the upstream reservoir group storage accounts for about $20 \%$ of the inflow of Xiluodu Reservoir, which can contribute to the actual dispatching work of Xiluodu Reservoir.
\end{abstract}

\section{Introduction}

The Jinsha River is the main stream of the upper reaches of the Yangtze River. It flows from Yushu,Qinghai to Yibin, Sichuan and flows through Qinghai, Tibet, Sichuan and Yunnan. The total length of the main stream is 3479 $\mathrm{km}$ and its natural drop is $5100 \mathrm{~m}$, its runoff is abundant and stable, and its water resources are abundant. It is the first of the three major hydropower bases. Among them, the middle reaches of the Jinsha River and the lower reaches of the Jinsha River are the focus of the current development. The middle reaches of the river section are developed by Longpan, Liangjiaren, Liyuan, Ahai, Jinanqiao, Longkaikou, Ludila and Guanyinyan. The downstream section is developed in accordance with the four-level plan of Wudongde, Baihetan, Xiluodu and Xiangjiaba. As the largest tributary of the Jinsha River, the Yalong River originates from the south of Bayan Kala Mountain and flows into the Jinsha River in Panzhihua, Sichuan. The total length of the main stream is $1571 \mathrm{~km}$, and the natural drop is $3870 \mathrm{~m}$. It is rich in water resources. Among them, the five cascades of Jinping I, Jinping II, Guandi, Ertan and Tongzilin in the lower reaches of the Yalong River have priority development conditions ${ }^{[1-2]}$.

At present, in the middle reaches of the Jinsha River, the six hydropower stations except the Longpan and the two families have been completed and put into operation ; in the lower reaches of the Jinsha River,Xiluodu and Xiangjiaba have been completed and put into operation, Wudongde and Baihetan are under construction, and the two power stations will be completed and put into operation in 2020; the five-level power stations in the lower reaches of the Yalong River have been completed and put into operation.

In the lower reaches of the Jinsha River, the XiluoduXiangjiaba cascade power station was put into operation in 2014. There are more than ten reservoirs in the middle reaches of the Jinsha River and the Yalong River basin above the cascade hydropower station. Among them, a total of eight key control reservoirs integrated into the Yangtze River Basin joint flood control dispatching are included. These control reservoirs have different scales, different operating characteristics, scattered locations, complex operational management and large uncertainties, which have a great impact on the forecast operation, planning and real-time scheduling of Xiluodu Reservoir ${ }^{[3-}$ 5].

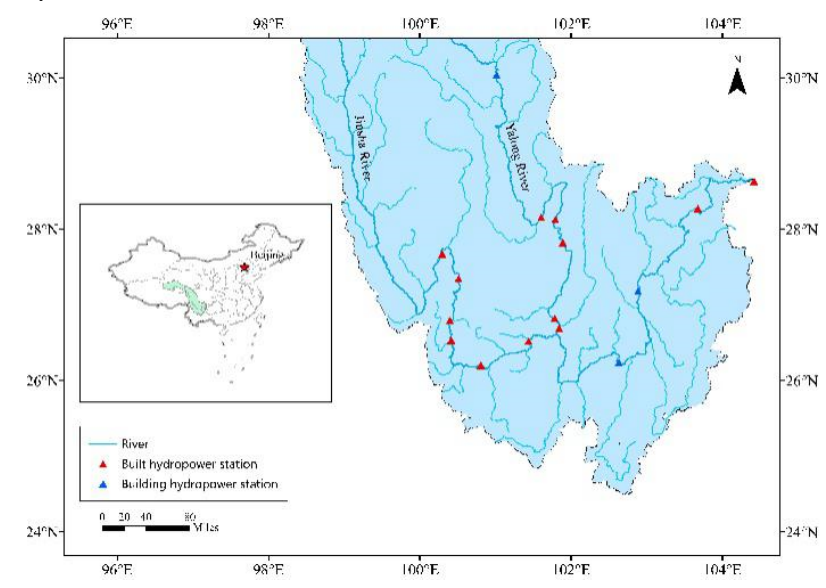

Figure 1. The distribution of the power stations in upper Yangtze River in China.

In view of this, the impacts on the regulation and storage of reservoirs in the upper reaches of the cascade hydropower stations on the lower reaches of the Jinsha River are analyzed, and the regulation rules are sorted out. On this basis, according to the planning and construction of the upstream river basin reservoir group, scientific prediction of the trend of the impact of regulation and storage will help the technicians to carry out the dispatching work of the Xiluodu reservoir more rationally

\footnotetext{
${ }^{a}$ Corresponding author: liang_zhiming $@$ ctg.com.cn
} 
and efficiently, and give full play to the XiluoduXiangjiaba cascade hydropower station's overall benefit.

\section{Overview of the upper reservoir group of Xiluodu}

According to the construction and operation of the reservoirs in the upper reaches of the Yangtze River, combined with the relevant documents of the National Defense General and the Yangtze River Defense General, considering the data of the reservoirs in the information sharing platform of the upper reaches of the Yangtze River, a total of 11 reservoirs of the watershed in the middle reaches of the Jinsha River and the Yalong River basin in the upper reaches of Xiluodu are determined to studied as research objects, and the research on the law of storage and regulation are carried out systematically.

Table 1. Generalized diagram of the upper reservoir group of Xiluodu

\begin{tabular}{|c|c|c|c|}
\hline Watershed & $\begin{array}{c}\text { Reservoir } \\
\mathrm{s}\end{array}$ & $\begin{array}{c}\text { Total storage } \\
\text { capacity }\end{array}$ & $\begin{array}{c}\text { Regulating } \\
\text { storage capacity }\end{array}$ \\
\hline \multirow{4}{*}{$\begin{array}{c}\text { Middle } \\
\text { reach } \\
\text { of Jinsha } \\
\text { River }\end{array}$} & Liyuan & 8.05 & 1.73 \\
\cline { 2 - 4 } & Ahai & 8.85 & 2.38 \\
\cline { 2 - 4 } & Jinanqiao & 9.13 & 3.47 \\
\cline { 2 - 4 } & Longkaik & 5.58 & 1.13 \\
\cline { 2 - 4 } & Ludila & 17.18 & 3.76 \\
\cline { 2 - 4 } & $\begin{array}{c}\text { Guanyiny } \\
\text { an }\end{array}$ & 22.5 & 5.55 \\
\hline \multirow{4}{*}{$\begin{array}{c}\text { Yalong } \\
\text { River }\end{array}$} & Ertan & 61.4 & 33.7 \\
\cline { 2 - 4 } & Tongzi & 0.91 & 0.15 \\
\cline { 2 - 4 } & JinpingI & 77.6 & 49.1 \\
\cline { 2 - 4 } & JinpingII & 0.19 & 0.05 \\
\cline { 2 - 4 } & Guandi & 7.6 & 1.12 \\
\hline
\end{tabular}

According to the statistics in Table 1, the total storage capacity of the upstream reservoir group of Xiluodu has reached 21.199 billion $\mathrm{m}^{3}$, and the storage capacity is 10.214 billion $\mathrm{m}^{3}$, which is about 1.39 times of the total regulation storage capacity of Xiluodu-Xiangjiaba cascade hydropower station. According to the analysis of the storage capacity of the cascade reservoirs in the upper reaches of Xiluodu, the water storage capacity of the Yalong River Basin is $82 \%$, and the

watershed of the Jinsha River is only $18 \%$. Among them, Jinping I has a proportion of $48 \%$ and Ertan has a ratio of $33 \%$. The Jinping I and Yalongjiang power stations are the main power stations affected by the regulation and storage of the cascade reservoirs in the upper reaches of Xiluodu.

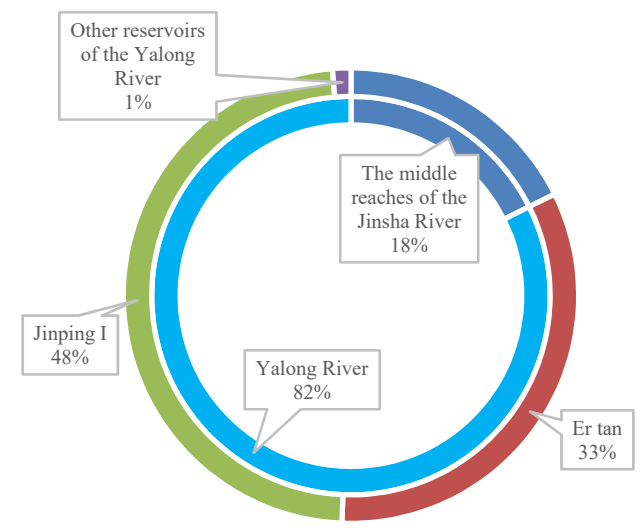

Figure 2. Each basin adjustment storage capacity ratio According to the "Reply on the Joint Dispatching Plan for the Upper Reaches of the Yangtze River in 2018" issued by the National Defense General (Guoxun [2018] No. 6), the controlling reservoirs under construction in the upper reaches of the Yangtze River mainly include Wudongde, Baihetan,Lianghekou, The collection of the characteristics of the six reservoirs is as the following table:

According to the planning and construction information of the lower reaches of the Jinsha River and the Yalong River Basin, it is expected that all units of the Wudongde Power Station will be put into operation at the end of 2021. By 2023, all units of the Baihetan Power Station and the Lianghekou Power Station will be put into operation. After all the three power stations are put into operation, the reservoir capacity of the reservoirs above Xiluodu will increase by 19.16 billion $\mathrm{m}^{3}$, reaching 29.374 billion $\mathrm{m}^{3}$, which is 3.99 times that of the Xiluodu-Xiangjiaba cascade power station. The further increase of the storage capacity of the cascade reservoirs in the upstream basin will also increase the impact on the storage flow of the Xiluodu Reservoir.

Table 2. Three key Reservoirs'Information

\begin{tabular}{|c|c|c|c|c|c|}
\hline \multirow{2}{*}{ Watershed } & Reserviors & $\begin{array}{c}\text { Basin area }\left(10^{4}\right. \\
\left.\mathrm{km}^{2}\right)\end{array}$ & $\begin{array}{c}\text { Total storage } \\
\text { capacity } \\
\left(10^{8} \mathrm{~m}^{3}\right)\end{array}$ & $\begin{array}{c}\text { Regulating storage } \\
\text { capacity }\left(10^{8} \mathrm{~m}^{3}\right)\end{array}$ & $\begin{array}{c}\text { Optimum production } \\
\text { time }\end{array}$ \\
\hline \multirow{2}{*}{ Jinsha River } & Wudongde & 40.61 & 76 & 26 & 2021 year \\
\cline { 2 - 6 } & Baihetan & 43.63 & 188 & 100 & 2023 year \\
\hline $\begin{array}{c}\text { Yalong } \\
\text { River }\end{array}$ & Lianghekou & 5.96 & 107.67 & 65.6 & 2023 year \\
\hline
\end{tabular}

\section{Analysis on Influence of Regulation and Storage of Cascade Reservoirs in the Upper Stream of Xiluodu Basin}

Select the water level data of 11 reservoirs in the upper reaches of Xiluodu River Basin. According to the different construction time, the length of the water level data sequence of each reservoir is different. Before the construction of the reservoir, the Xiluodu Reservoir used the flow of Pingshan Station as the inflow. According to the water level-storage relationship curve of each hydropower station, the data sequence of the storage capacity of each power station is obtained by interpolation. According to the data of the 
adjacent time period and the water balance formula, the water storage capacity and the storage flow value of each power station are calculated. The calculation formula is as follows:

$$
\left\{\begin{array}{c}
W_{t x}=-\left(V_{t+1}-V_{t}\right) \\
Q_{t x}=W_{t x} / \Delta t
\end{array}\right.
$$

Among them, $W_{t x}$ is the amount of water storage, $Q_{t x}$ is regulating flow, $V_{t+1}$ is the storage capacity at the end of the t period, $V_{t}$ is the initial storage value of the $\mathrm{t}$ period, $\Delta t$ 为is the duration of $\mathrm{t}$ 。

According to the calculation formula, it can be known that:when $Q_{t x}\left(W_{t x}\right)>0$, it means that the reservoir is discharging, $Q_{t x}\left(W_{t x}\right)$ is discharging flow (the amount of discharging flow ) ; when $Q_{t x}\left(W_{t x}\right)<0$, it means that the reservoir is charging, $Q_{t x}\left(W_{t x}\right)$ is charging flow (the amount of charging flow) 。

In order to effectively measure the impact of upstream reservoir group storage, the following indicators are defined:

Adjustment ratio $R_{t x}$ : Regulate flow in the upper reservoir group $R_{t x}$ divided by Xiluodu inflow $Q_{r k}$, measuring the proportion of the influence of storage in upstream reservoirs to the actual inflow of the Xiluodu.

Absolute value of adjustment ratio $\left|R_{t x}\right|$ : Because the adjustment ratio can be positive or negative, in order to measure the overall impact of the upstream reservoir group, the absolute value of the adjustment ratio is introduced. 。

According to the above-mentioned calculation method of storage flow and corresponding statistical indicators, the 11 reservoirs's water storage capacity in the upstream reservoir group are separately calculated, and the storage flow (water volume) of each reservoir is accumulated by the basin to obtain the various watersheds. Then the flow rate (water volume) is obtained in a timely manner. Taking Xiluodu Reservoir as a research node, the influence of upstream reservoir group storage on Xiluodu Reservoir is studied.

From the aspects of overall regulation and storage level, stage analysis of water storage and storage in each basin, the impact analysis on the storage of Xiluodu upstream reservoir group from 2006 to 2016 is carried out.

\subsection{Integral regulating level}

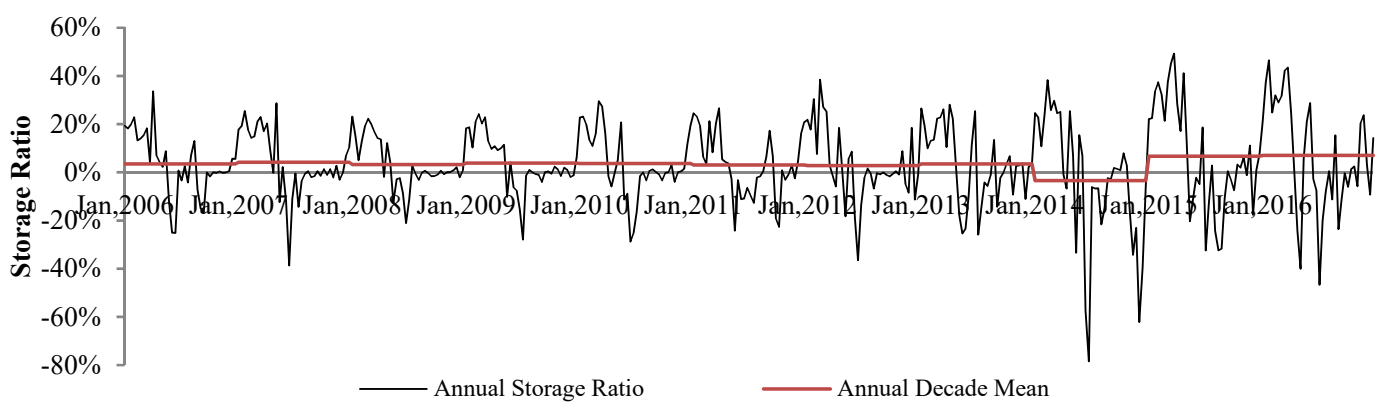

Figure 3. Ratio of regulation storage in the upper reservoirs of Xiluodu

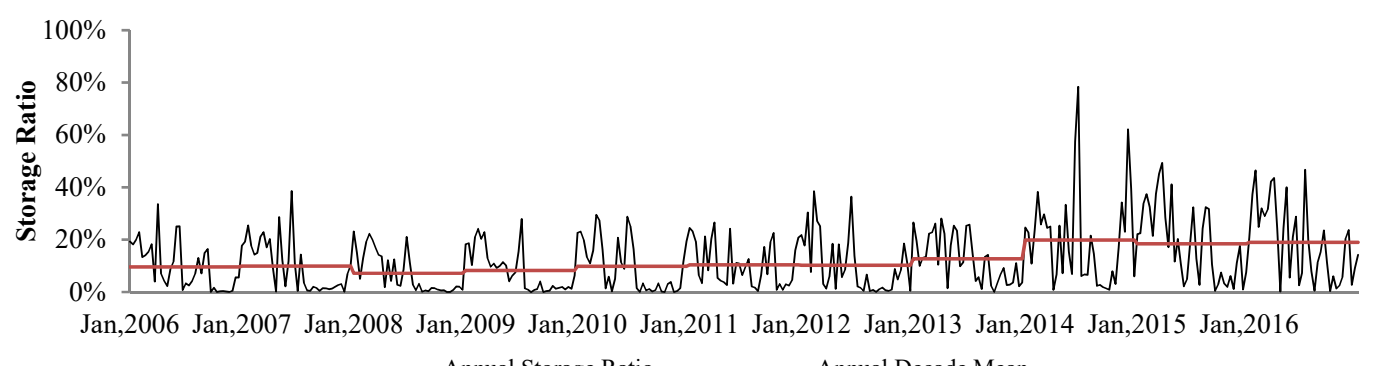

Figure 4. Absolute value of the regulation storage in the upper reservoirs of Xiluodu

According to the above definition, regulation storage in the upper reservoirs of Xiluodu is plotted (Fig. 3). The absolute value of the regulation storage is proportional to the process chart (Fig. 4). According to the analysis, the upstream reservoir group's regulation storage accounted for about $10 \%$ of the total in 2006-2014. In 2014, the overall storage level was greatly improved, and it was stable at nearly $20 \%$ in 2014-2016. The maximum flow ratio occurred in mid-June 2014 , which was $78.39 \%$. The upstream reservoir group storage greatly affected the natural inflow of the Xiluodu Reservoir, which had a great impact on the operation of the Xiluodu Reservoir.

\subsection{Regulation storage analysis in each season}

According to the operation characteristics of Xiluodu Reservoir, a complete hydrological year is divided into flood 
season (July-August), water storage season (September) and other seasons. The annual water storage and flood season of the upper reservoir of Xiluodu are counted in 2006-2016. Adjusting regulation storage data in these seasons and conducting comparative analysis, we can see that: A. During 2006-2016, the amount of water storage has basically increased year by year. The other seasons in the storage of water accounted for a large proportion. The average value for many years was $75.32 \%$. The flood season accounted for $1 / 6$ of the whole year, and the water storage accounted for $19.39 \%$ of the whole year;
B. From 2006 to 2016 , the average annual storage capacity during the flood season was 2.588 billion $\mathrm{m}^{3}$, the water storage season was 580 million $\mathrm{m}^{3}$, and the other period was 8.859 billion $\mathrm{m}^{3}$. The average water inflow of Xiluodu during the flood season was 46.027 billion $\mathrm{m} 3$, and the s storage ratio was $5.62 \%$. In other seasons, the average inflow was 63.429 billion $\mathrm{m} 3$, and the storage ratio was $14 \%$. It can be seen that in other seasons, Xiluodu is more sensitive to the impact of upstream reservoirs. Therefore, when formulating annual power generation plans and making real-time decisions, we should pay attention to the impact of upstream reservoirs on Xiluodu during other seasons.

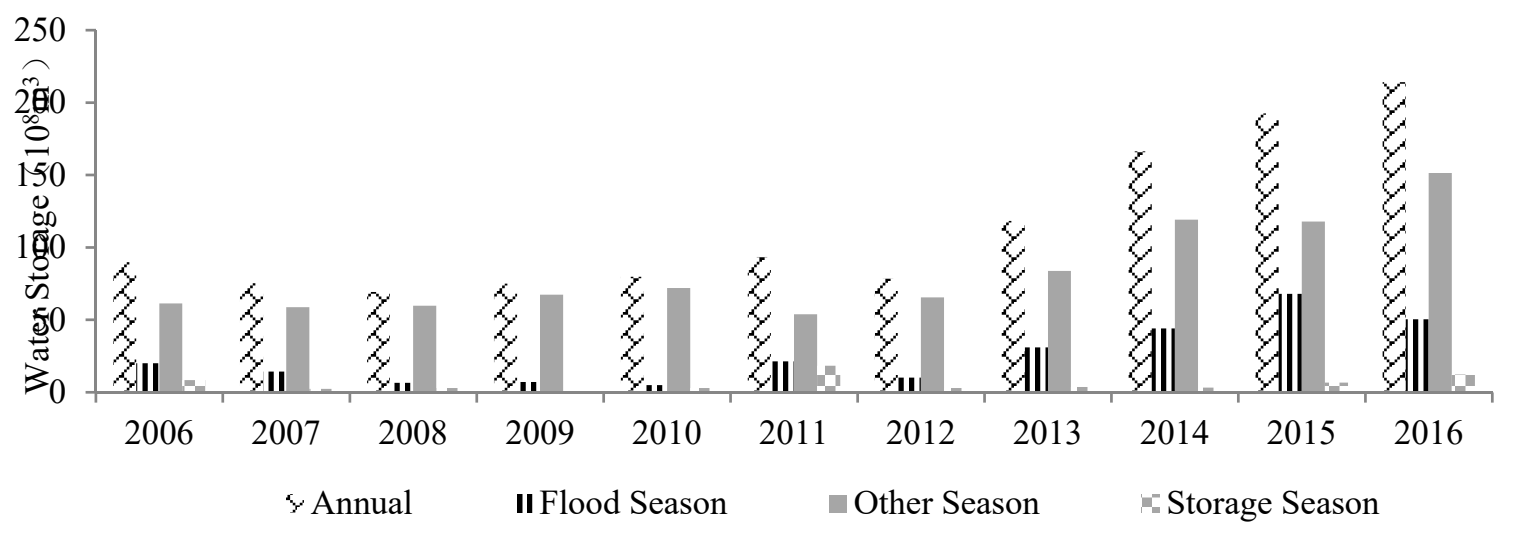

Figure 5. Comparison of regulation storage in each season

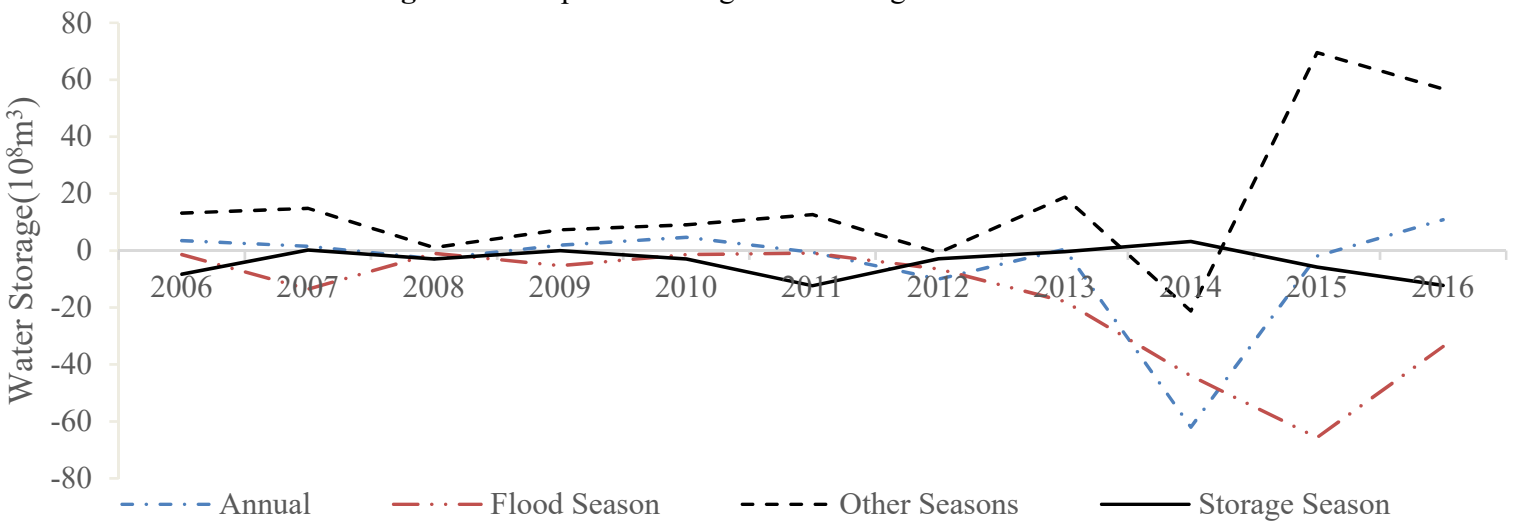

Figure 6. Regulation storage process from 2006 to 2016

According to the analysis of the annual storage and storage process of the upstream distribution of the Xiluodu upstream reservoir from 2006 to 2016 (Fig. 5-6), it can be seen that due to the problems such as the initial storage and storage time of the upstream reservoir group in the research year, each year The adjustment process has changed a lot, lacking general rules, but there are basic patterns of water storage during the flood season and water storage in other periods. From the perspective of the general regulation and storage process, during the flood season, the average intercepted flood volume of the upstream reservoir of Xiluodu was 1.739 billion $\mathrm{m} 3$, the maximum was 2015, and the intercepted flood storage was 6.566 billion $\mathrm{m} 3$. During the storage period, the average storage capacity of the upstream reservoir group was At the end of 2011, the maximum amount of water storage was 1.234 billion $\mathrm{m} 3$. In other periods, the average replenishment of the upstream reservoir group was 1.647 billion $\mathrm{m} 3$, and the maximum appeared in 2015, with a water replenishment of 6.953 billion $\mathrm{m}^{3}$.

\subsection{Regulation storage analysis by basins}




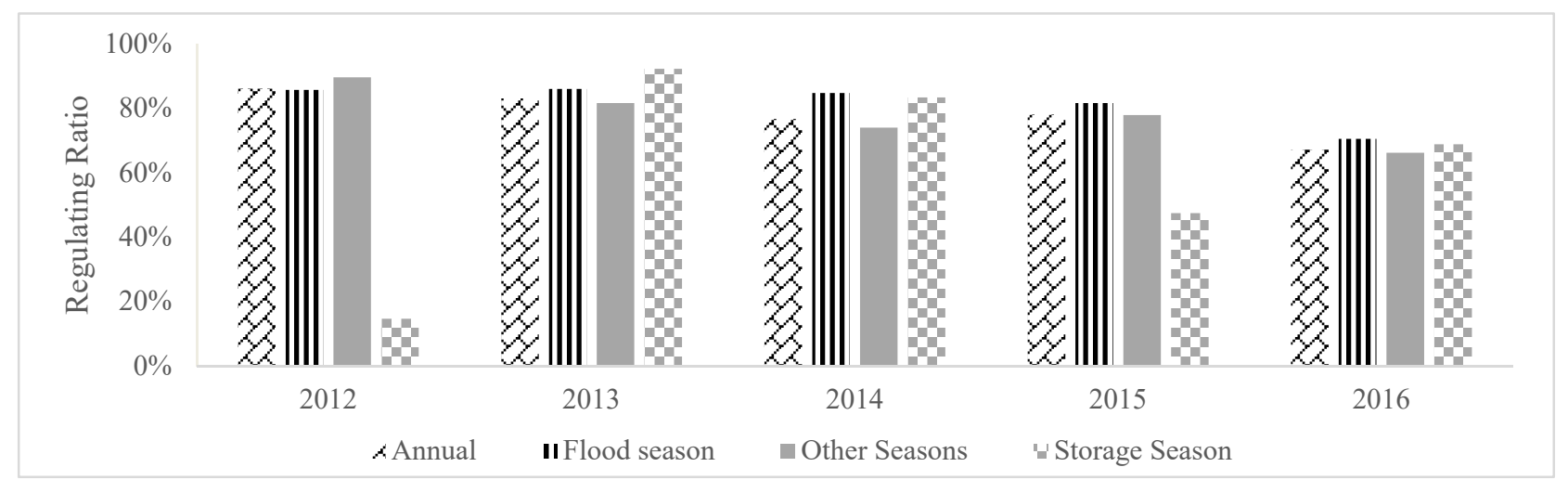

Figure 7. Ratio of regulation storage in Yalong River

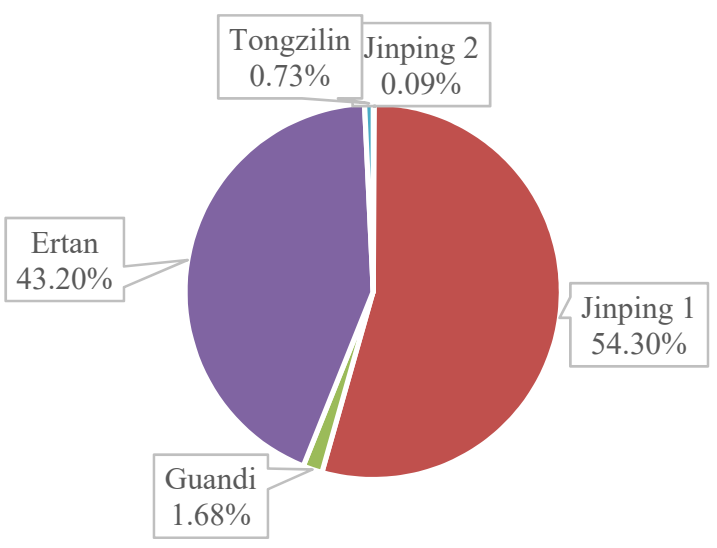

Figure 8. Regulation storage ratio of each reservoir in Yalong River

Since the cascade hydropower stations in the middle reaches of the Jinsha River have been put into operation after 2012, the reservoirs affected by the upstream regulation of Xiluodu were mainly distributed in the Yalong River basin before 2012. After 2012, with the successive commissioning of several hydropower stations in the middle reaches of the Jinsha River, the proportion of storage in the middle reaches of the Jinsha River has gradually increased, and the proportion of storage in the Yalong River Basin has shown a downward trend year by year. By 2016, the proportion of storage is still more than $67 \%$; The proportion of water storage capacity in the Yalong River Basin is divided. It can be seen that the Jinping I Hydropower Station accounts for $54.3 \%$, and the Ertan Hydropower Station accounts for $43.2 \%$, and the two reservoirs adjust the storage capacity. More consistent than the basic, Xiluodu storage flow is mainly affected by Jinping I and Ertan regulation.

\section{Conclusions}

This paper starts with the regulation ability analysis of cascade reservoirs in the upper reaches of Xiluodu Reservoir, and explores the impact of reservoirs regulation on the operation of Xiluodu Reservoir. The influence degree of the overall regulation and storage of the upstream reservoir group on the inflow of the Xiluodu reservoir was quantitatively analyzed.
The type, scope and level of the influence of the upstream reservoir group on the distribution of the Xiluodu reservoir were analyzed systematically. A preliminary discussion on the storage ratio and storage in each basin was carried out, and the degree of impact on the regulation and storage of each basin was clarified. The corresponding research results can provide an effective reference for the formulation and real-time scheduling of the medium and long-term power generation plan of Xiluodu Reservoir. The next step will be to discuss the regulation and regulation of the operation of cascade hydropower stations in each basin, and try to extract the general laws to provide technical support for the optimal dispatch of Xiluodu Reservoir.

\section{References}

1. Shu WM, Li QP, et al. Impact of Dispatching of Reservoirs in the Upper Yangtze River on Inflow Forecast of the Three Gorges Reservoir. Hydropower and new energy, 2016(5):1-5.

2. Jin XP. Study on co-regulation of reservoirs in upper reaches of Changjiang River in 2016 for flood control. Yangtz e River, 2017, 48(4):22-27.

3. L XR, L YL, Q H. Study on Compensation Benefits of Joint Dispatching for Multi-owner Cascade Hydropower Station in Jinshajiang and Yalongjiang Rivers. Water Resources and Power.2016,34(01):6165.

4. Cheng CT, Chau KW, Wu XY, Shen JJ. Fast-growing China's hydropower systems and operation challenges. World Environ Water Resour Congr 2011:20-9.

5. Li JQ, Zhang YS, Ji CM, Wang AJ, Lund JR. Largescale hydropower system optimization using dynamic programming and object-oriented programming: the case of theNortheast China Power Grid. Water Sci Technol 2013;68(11):2458-67. 